\title{
Hepatocyte growth factor mimetic protects lateral line hair cells from aminoglycoside exposure
}

\author{
Phillip M. Uribe ${ }^{1}$, Leen H. Kawas ${ }^{1,2}$, Joseph W. Harding ${ }^{1,2}$ and Allison B. Coffin ${ }^{1,3} *$ \\ ${ }^{1}$ Department of Integrative Physiology and Neuroscience, Washington State University, Pullman, WA, USA \\ ${ }^{2}$ M3 Biotechnology, Inc., Seattle, WA, USA \\ ${ }^{3}$ College of Arts and Sciences, Washington State University, Vancouver, WA, USA
}

Edited by:

Tycho M. Hoogland, Netherlands Institute for Neuroscience,

Netherlands

Reviewed by:

Mark E. Warchol, Washington

University School of Medicine, USA

Jonathan I. Matsui, Harvard

University, USA

${ }^{*}$ Correspondence:

Allison B. Coffin, College of Arts and Sciences, Washington State

University, 14204 NE Salmon Creek

Avenue, Vancouver, WA

98686-9600, USA

e-mail: allison.coffin@

vancouver.wsu.edu
Loss of sensory hair cells from exposure to certain licit drugs (e.g., aminoglycoside antibiotics, platinum-based chemotherapy agents) can result in permanent hearing loss. Here we ask if allosteric activation of the hepatocyte growth factor (HGF) cascade via Dihexa, a small molecule drug candidate, can protect hair cells from aminoglycoside toxicity. Unlike native HGF, Dihexa is chemically stable and blood-brain barrier permeable. As a synthetic HGF mimetic, it forms a functional ligand by dimerizing with endogenous HGF to activate the HGF receptor and downstream signaling cascades. To evaluate Dihexa as a potential hair cell protectant, we used the larval zebrafish lateral line, which possesses hair cells that are homologous to mammalian inner ear hair cells and show similar responses to toxins. A dose-response relationship for Dihexa protection was established using two ototoxins, neomycin and gentamicin. We found that a Dihexa concentration of $1 \mu \mathrm{M}$ confers optimal protection from acute treatment with either ototoxin. Pretreatment with Dihexa does not affect the amount of fluorescently tagged gentamicin that enters hair cells, indicating that Dihexa's protection is likely mediated by intracellular events and not by inhibiting aminoglycoside entry. Dihexa-mediated protection is attenuated by co-treatment with the HGF antagonist 6-AH, further evidence that HGF activation is a component of the observed protection. Additionally, Dihexa's robust protection is partially attenuated by co-treatment with inhibitors of the downstream HGF targets Akt, TOR and MEK. Addition of an amino group to the $\mathrm{N}$-terminal of Dihexa also attenuates the protective response, suggesting that even small substitutions greatly alter the specificity of Dihexa for its target. Our data suggest that Dihexa confers protection of hair cells through an HGF-mediated mechanism and that Dihexa holds clinical potential for mitigating chemical ototoxicity.

Keywords: zebrafish, hair cell protection, hearing loss, aminoglycosides, hepatocyte growth factor, lateral line

\section{INTRODUCTION}

Hearing loss and vestibular dysfunction are some of the most prevalent and debilitating disorders due to social isolation resulting from sensory deprivation. Particularly among the elderly, those with untreated hearing loss are less likely to participate in social activities and more likely to report levels of depression and anxiety (Bess et al., 1989; Knutson and Lansing, 1990). Hearing loss can result from excessive exposure to loud noise, genetic factors, or exposure to certain licit drugs, termed ototoxins, such as aminoglycoside antibiotics and platinumbased chemotherapeutics like cisplatin (Fee, 1980; Rybak et al., 2009). Due to their high efficacy, many ototoxins are still used despite the risk of hearing loss. Aminoglycoside antibiotics are still widely used for a variety of clinical applications. For example, cystic fibrosis patients suffer from severe gramnegative bacterial infections and are commonly prescribed the aminoglycoside antibiotics amikacin or tobramycin, despite as high as a 14\% incidence of hearing loss (Cheng et al., 2009).
Cisplatin use carries an even higher reported incidence of hearing loss, between $28-68 \%$, but it is used to treat several types of soft tissue tumors and is the most commonly prescribed chemotherapeutic for ovarian cancer (Rybak, 2007; Musial-Bright et al., 2011).

The primary cellular basis for ototoxic hearing loss is the death of sensory hair cells within the cochlea. Hair cells are mechanosensitive receptors in the inner ear that detect sounds and head movements; in mammals, loss of these cells is permanent and irreversible. There are currently no food and drug administration (FDA) approved treatments for the prevention of toxin-induced hair cell loss. Identification of a preventative therapy would allow for continued use of these efficacious antibiotics and chemotherapeutics without the devastating ototoxic consequences that accompany their use. Our work identifies a new otoprotective drug that is already designed for the clinical environment, allowing for quick transition to clinical use. 
Studies involving acoustic and chemical insults show that growth factors represent a compelling class of otoprotective compounds (Yagi et al., 1999; Shoji et al., 2000; Kawamoto et al., 2003; Liu et al., 2008). Hepatocyte growth factor (HGF), a potent neurotrophic factor, affects a variety of neuronal cell types to promote axon guidance and cell survival (Ebens et al., 1996; Miyazawa et al., 1998). Direct application of exogenous HGF onto cochlear explants protects hair cells from neomycin ototoxicity (Kikkawa et al., 2009). However, HGF itself does not represent a viable preventative therapeutic due to low blood-brain barrier permeability and a half-life of only $3.8 \mathrm{~min}$ (Appasamy et al., 1993). One study attempted to circumvent these constraints by using viral HGF gene delivery to the inner ear to drive constitutive HGF expression (Oshima et al., 2004). This viral HGF gene delivery approach protected rat cochlear hair cells from kanamycin ototoxicity, further evidence for a protective role of HGF in the auditory periphery. Unfortunately, viral gene therapy presents the risk of insertional mutagenesis and does not reliably yield high expression profiles (Monahan and Samulski, 2000). However, development of a small molecule capable of stimulating HGF, and its associated receptor c-Met, may be clinically efficacious.

The HGF mimetic Dihexa is a synthetically derived Angiotensin IV analog that is blood-brain barrier permeable, stable, and orally bioavailable (McCoy et al., 2013). McCoy et al. (2013) found that Dihexa treatment ameliorated memory loss in a rat model of Parkinson's Disease. Dihexa can bind to and dimerize HGF, forming a functional ligand and thereby activating c-Met (Benoist et al., 2014). HGF signaling is linked to neural protection in rodents both in vitro and in vivo, making a strong case for a small molecule activator of $\mathrm{HGF} / \mathrm{c}-\mathrm{Met}$ to confer a neuroprotective benefit (Zhang et al., 2000; Niimura et al., 2006). Here, we examine the otoprotective effects of Dihexa in a zebrafish model of chemical ototoxicity.

The experimental value of zebrafish as an animal model for in vivo drug discovery has grown rapidly due to their ease of assessment, large clutch size, and ability to recapitulate human disease conditions (MacRae and Peterson, 2003). The larval zebrafish lateral line is an especially tractable model for the identification of compounds that prevent hair cell loss (Coffin et al., 2010; Esterberg et al., 2013). The lateral line system of teleost fishes is an externally located, mechanosensitive sensory system used to detect vibrations in the aquatic environment that aid in predator detection, prey avoidance, and schooling behavior (Coombs et al., 1989). Hair cells of the lateral line are structurally and functionally similar to those of the mammalian inner ear and, perhaps more importantly, respond similarly to toxins (Harris et al., 2003; Ou et al., 2007; Coffin et al., 2013b). Previous drug discovery work in the larval zebrafish lateral line identified the novel compound PROTO-1 that prevents aminoglycoside-induced hair cell toxicity in rodent models in vivo, demonstrating that otoprotective drug discovery in zebrafish translates to mammalian systems (Owens et al., 2008; Rubel et al., 2011).

In this study, we demonstrate that Dihexa protects lateral line hair cells from aminoglycoside ototoxicity. Dihexa does not alter the entry of aminoglycosides into hair cells but rather attenuates cell death through an HGF-dependent signaling mechanism. This work demonstrates the potential clinical utility of Dihexa as a co-administered protectant to prevent aminoglycoside ototoxicity.

\section{MATERIALS AND METHODS ANIMALS}

Larval zebrafish $\left({ }^{*} \mathrm{AB}\right)$ were obtained through pair-wise matings and raised at $28.5^{\circ} \mathrm{C}$ in petri dishes (Westerfield, 2000). All zebrafish were maintained on a $14 \mathrm{~h}$ light/10 h dark cycle in the Coffin Lab zebrafish facility at Washington State University, Vancouver. Embryos were raised until 5 or 6 days postfertilization (dpf) prior to experimentation because larvae younger than $5 \mathrm{dpf}$ exhibit some resistance to aminoglycoside ototoxicity (Murakami et al., 2003; Santos et al., 2006). Transgenic Brn3c:mGFP zebrafish were used for direct hair cell counts and c-Met localization studies. Brn3c:mGFP fish express membrane bound GFP in hair cells under control of the Brn3c (aka Pou4f3) promoter (Xiao et al., 2005). Previous work has demonstrated that GFP positive cells in Brn3c:mGFP fish co-label with phalloidin staining and thus can be used a reliable marker of mature hair cells (Uribe et al., 2013). All experimental procedures were approved by the Washington State University Animal Care and Use Committee.

\section{HGF RECEPTOR LOCALIZATION}

Immunohistochemistry was performed using 1:500 anti-Met (Cell Signaling, Danvers, MA). Following fixation in $4 \%$ paraformaldehyde (PFA), 5 dpf Brn3c:mGFP larvae, which express membrane-bound GFP in hair cells, were rinsed twice with phosphate-buffered saline (PBS) for $10 \mathrm{~min}$ each and then once with $\mathrm{dH}_{2} \mathrm{O}$ for $20 \mathrm{~min}$. Larvae were then placed into blocking solution, which consisted of $5 \%$ goat serum in PBST $(0.1 \%$ Triton $\mathrm{x}-100$, Sigma) for $1 \mathrm{~h}$. Fish were then incubated overnight at $4^{\circ} \mathrm{C}$ in anti-Met in PBST with $1 \%$ goat serum. Excess primary antibody was washed off by three $10 \mathrm{~min}$ PBST rinses. Fish were then incubated for $4 \mathrm{~h}$ in 1:500 Alexa Fluor 568 secondary antibody (Life Technologies) diluted in PBST at room temperature. Excess secondary antibody was washed off by 3 consecutive 10-min rinses with PBST. Labeled larvae were then rinsed once with $\mathrm{PBS}$ and stored in 1:1 PBS:glycerol for confocal imaging. Adult ${ }^{*} \mathrm{AB}$ liver was removed and fixed for identical tissue processing (Gupta and Mullins, 2010).

\section{DRUG TREATMENTS}

Neomycin $(10 \mathrm{mg} / \mathrm{mL})$ and gentamicin $(50 \mathrm{mg} / \mathrm{mL})$ solutions (Sigma-Aldrich; St. Louis, MO) were diluted in E2 embryo medium (EM; $1 \mathrm{mM} \mathrm{MgSO} 4,120 \mu \mathrm{M} \mathrm{KH} \mathrm{KO}_{4}, 74 \mu \mathrm{M}$ $\mathrm{Na}_{2} \mathrm{HPO}_{4}, 1 \mathrm{mM} \mathrm{CaCl}_{2}, 500 \mu \mathrm{M} \mathrm{KCl}, 15 \mathrm{mM} \mathrm{NaCl}$, and $500 \mu \mathrm{M}$ $\mathrm{NaHCO}_{3}$ in $\mathrm{dH}_{2} \mathrm{O}$; Westerfield, 2000) to working concentrations of 25-400 $\mu \mathrm{M}$. Cisplatin stock ( $1 \mathrm{mg} / \mathrm{mL}$; WG Critical Care; Paramus, NJ) was diluted in EM to working concentrations of $500-1000 \mu \mathrm{M}$ and the $\mathrm{pH}$ adjusted to 7.2 , since the cisplatin stock is highly acidic. Dihexa was synthesized by RS Synthesis (Louisville, KY) with a purity of $95.1 \%$. 
Free swimming zebrafish larvae were placed in 6-well plates and exposed to ototoxin in the presence or absence of Dihexa. Fish were pretreated with Dihexa or vehicle dimethyl sulfoxide (DMSO) control for $1 \mathrm{~h}$. Fish were then co-treated with Dihexa or DMSO and neomycin (30 min), acute gentamicin (30 min), chronic gentamicin $(6 \mathrm{~h})$, or cisplatin $(4 \mathrm{~h})$. Ototoxin exposure times were selected based on previous work (Ou et al., 2007; Coffin et al., 2009; Owens et al., 2009). Fish were then rinsed three times in EM. Gentamicin (chronic) and cisplatin exposed groups and associated controls were assessed immediately following the three EM washes. Fish treated acutely with neomycin or gentamicin, and their associated controls, were allowed to recover in EM for 45 min prior to hair cell assessment.

\section{HAIR CELL ASSESSMENT}

Survival of lateral line hair cells was assessed by vital dye labeling in live fish. The vital dye 2-(4-(dimethylamino)styryl)$N$-ethylpyridinium iodide (DASPEI) (Life Technologies, Grand Island, NY) is a marker of mitochondrial membrane potential and preferentially stains lateral line hair cells when added to the surrounding EM (Harris et al., 2003). Fish were incubated in 0.005\% DASPEI for $15 \mathrm{~min}$, then rinsed twice with EM and anesthetized with 0.001\% MS-222 (Argent Labs, Redmond, WA). Using a Leica M165FC fluorescence dissection scope, 10 anterior neuromasts (IO1, IO2, IO3, IO4, M2, MI1, MI2, O2, SO1, and SO2; see Raible and Kruse, 2000) per fish were assessed based on fluorescent intensity (Harris et al., 2003; Coffin et al., 2009; Owens et al., 2009). An intensity score of 2 signifies intense neuromast fluorescence, an intermediate score of 1 represents faint DASPEI labeling, while a 0 neuromast score equates to the absence of neuromast fluorescence at a given neuromast's stereotyped position. The scores from 10 neuromasts for each fish were summed such that each larva receives a final score between 0 (no neuromast fluorescence) and 20 (full complement of hair cells in all 10 neuromasts). To obtain direct hair cell counts from Brn3c:mGFP fish, we fixed larvae post-treatment in 4\% PFA overnight at $4^{\circ} \mathrm{C}$. Fish were rinsed with PBS three times, placed in 1:1 PBS:glycerol, and mounted on bridged coverslips. Hair cell counts for 5 anterior neuromasts (IO1, IO2, IO3, M2, and OP1) per fish were obtained and summed.

\section{AMINOGLYCOSIDE UPTAKE}

Gentamicin conjugated to the fluorophore Texas Red (GTTR) was used to determine if Dihexa affected aminoglycoside uptake by hair cells (Steyger et al., 2003). Larvae were pretreated with Dihexa or DMSO for $1 \mathrm{~h}$, then co-treated with GTTR for $3 \mathrm{~min}$, rinsed 4 times in EM for $30 \mathrm{~s}$ each, and fixed in $4 \%$ PFA overnight at $4{ }^{\circ} \mathrm{C}$ (Owens et al., 2008). GTTR-labeled neuromasts were visualized using a Leica SP8 confocal microscope, keeping gain and laser intensity values constant for a given experiment. Z-stack images of O2, MI1, and MI2 neuromasts were collected and compressed using Leica LAS AF software. Neuromasts were masked using a line tool and mean fluorescence was measured for an entire neuromast using Image version 1.48 (National Institutes of Health, Bethesda, MD), mean background fluorescence was then subtracted out to yield net mean fluorescence for each neuromast.

\section{PHARMACOLOGICAL INHIBITORS}

Pharmacological inhibition of $\mathrm{HGF} / \mathrm{c}-\mathrm{Met}$ or its downstream targets was used to elucidate which factors are important for Dihexa-mediated otoprotection. All inhibitors used were co-administered with Dihexa, that is $1 \mathrm{~h}$ pretreatment and co-treatment with a given ototoxin. 6-AH is a metabolically stable antagonist to the $\mathrm{HGF} / \mathrm{c}-\mathrm{Met}$ system that works by preventing HGF dimerization and activation (Kawas et al., 2012). We used $1 \mu \mathrm{M}$ 6-AH as this concentration did not affect fish health or alter hair cell loss in response to neomycin but did attenuate neomycin-induced hair cell death. We used $10 \mu \mathrm{M}$ rapamycin, a TOR inhibitor, (GenDEPOT, Barker, TX) as this concentration had no affect on neomycin ototoxicity or fish health but attenuated Dihexa hair cell protection in preliminary experiments. Rapamycin concentrations as high as $50 \mu \mathrm{M}$ were tested initially and no overall toxicity was observed. We conducted similar optimization experiments with the MEK inhibitor, UO126 and an Akt inhibitor (CAS 61284709-3; both inhibitors from EMD Millipore, Billerica, MA), selecting $1 \mu \mathrm{M}$ as the optimal concentration of each compound. For both UO126 and Akt inhibitor, the highest concentration tested was $10 \mu \mathrm{M}$ and we observed no overt toxicity at this concentration.

\section{STATISTICAL ANALYSIS}

Data were analyzed using GraphPad Prism (V. 6.0, La Jolla, CA). Statistical analyses were performed using either an un-paired $t$-test assuming equal variance, one-, or two-way ANOVA, as appropriate, and are specifically indicated on each figure legend. Post hoc comparisons were performed using Bonferonni corrections. Statistical values for ototoxin were omitted from figure legends because it is established that they cause a dose-dependent decrease in hair cell survival, in other words, we know that a dose-response curve for neomycin only will be statistically significant. All data are presented as mean \pm s.e.m.

\section{RESULTS}

\section{C-MET EXPRESSION IN LARVAL ZEBRAFISH NEUROMASTS}

We immunohistochemically processed 5 dpf Brn3c:mGFP larvae using anti-c-Met to determine if c-Met expression is present in anterior lateral line neuromasts. In these fish, GFP localizes to the hair cell membrane, allowing for easy delineation of cell boundaries (Figure 1A). c-Met expression was widespread in the skin epithelium, including in neuromasts (red punctae in Figure 1B). No red punctae were present in a secondary antibody only control that was not incubated in anti-c-Met (Figures 1D-F). c-Met labeling is present both in hair cells and in other cell types in the neuromast (Figure 1C). To verify the validity of observed c-Met expression in hair cells, adult ${ }^{*} \mathrm{AB}$ liver tissue was immunohistochemically processed for anti-c-Met and DAPI (blue). c-Met expression in the adult liver is widespread and punctate, similar to the neuromast expression profile (Figure 1G). These results indicate that our c-Met labeling is reliable and that anterior lateral line neuromasts should be receptive to c-Met modulation. 

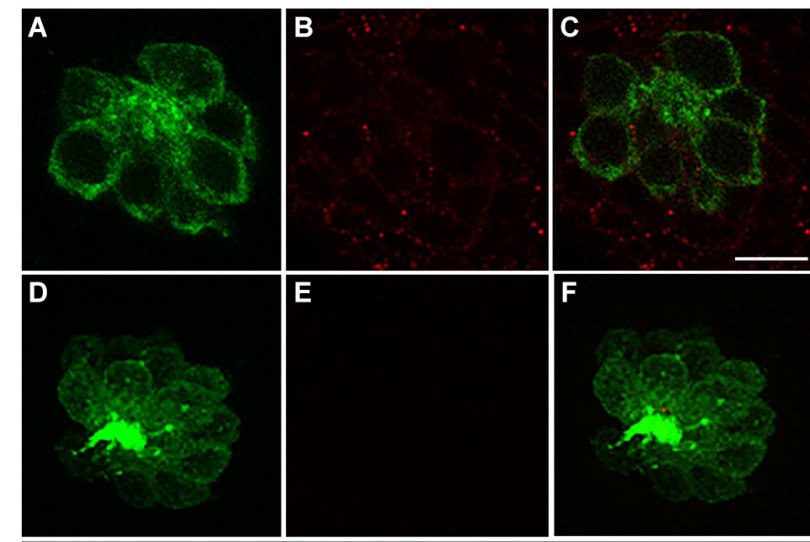

G

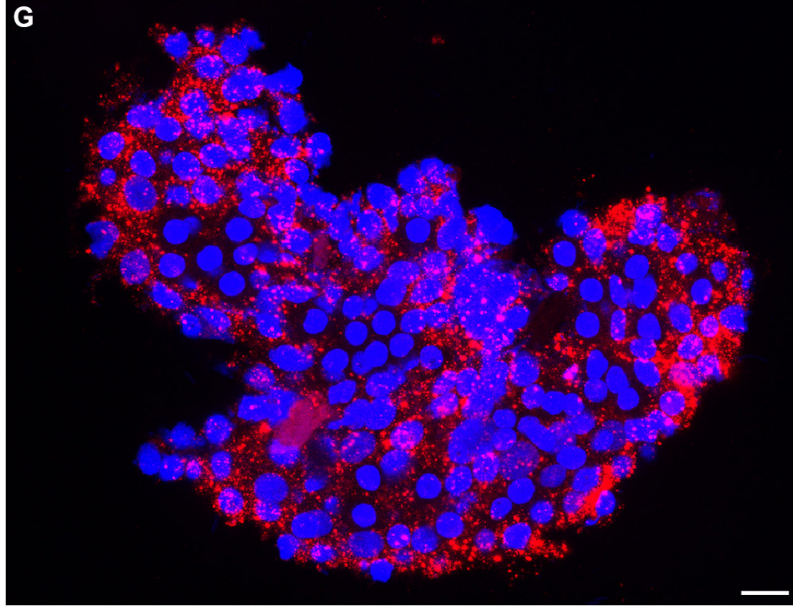

FIGURE 1 | c-Met is expressed in lateral line neuromasts

(A) Neuromast of a Brn3c:mGFP transgenic zebrafish with clearly labeled hair cell boundaries. (B) Anti-c-Met labeling (red punctae) is present throughout the neuromast. (C) Merged image shows c-Met is present near the hair cell membrane and in surrounding cells. (D-F) Brn3c:mGFP larvae incubated with secondary antibody only show no c-Met labeling. (G) *AB adult liver tissue labeled with DAPI (blue) and anti-c-Met (red) demonstrates robust, punctate c-Met expression. Scale bar in (C) represents $5 \mu \mathrm{m}$ and applies to images (A-F). Scale bar in (G) represents $5 \mu \mathrm{m}$.

\section{DIHEXA PROTECTS LATERAL LINE HAIR CELLS FROM ACUTE AMINOGLYCOSIDE TOXICITY}

Treatment with Dihexa confers protection from neomycin in a dose-dependent manner (Figure 2A). Untreated controls labeled with the vital dye DASPEI display bright neuromast fluorescence (Figure 2A inset). In contrast, animals treated with $200 \mu \mathrm{M}$ neomycin for thirty minutes exhibit dim or completely absent fluorescence. The greatest protection was found at $10^{-6} \mathrm{M}$ (1 $\mu \mathrm{M})$, where only a minor decrease from control hair cell survival scores was observed. An additional peak of protection was seen at $10^{-13} \mathrm{M}$ (100 $\left.\mathrm{fM}\right)$ but was inconsistent across experiments, so all additional experiments were run with $10^{-6} \mathrm{M}$ $(1 \mu \mathrm{M})$ Dihexa. Figure $2 \mathrm{~B}$ shows that $10^{-6} \mathrm{M}(1 \mu \mathrm{M})$ Dihexa significantly protects hair cells from a range of neomycin concentrations. Additionally, there was no observed toxicity of Dihexa treatment alone. Dihexa also protects hair cells from variable concentrations of acute gentamicin (Figure 2C).
Previous work has demonstrated that aminoglycosides activate acute and slow (chronic) mechanisms that are distinct from one another, with neomycin only activating acute mechanisms but gentamicin activating both pathways (Coffin et al., 2009, 2013b; Owens et al., 2009). To ask if Dihexa can modulate both mechanisms of aminoglycoside-induced hair cell death, Dihexa pretreatment was followed by $6 \mathrm{~h}$ chronic gentamicin co-treatment. Dihexa was not protective against chronic gentamicin exposure (Figure 2D). Since slow-acting cell death processes can proceed following ototoxin removal (Owens et al., 2009), we next asked if Dihexa-mediated protection was still present $6 \mathrm{~h}$ after neomycin exposure. Dihexa-mediated protection was still robust $6 \mathrm{~h}$ post-neomycin washout (data not shown).

To verify DASPEI scores, fish from the same treatment groups were fixed and immunohistochemically processed with antiparvalbumin (Millipore) to visualize hair cells (see Coffin et al., 2013b for details) (data not shown). Direct hair cell counts were also obtained from Brn3c:mGFP fish, further demonstrating that Dihexa robustly protects hair cells from neomycin damage (Figure 3).These results indicate that Dihexa only modulates targets responsible for the acute phase of aminoglycoside ototoxicity.

\section{DIHEXA DOES NOT BLOCK GENTAMICIN UPTAKE INTO HAIR CELLS}

Certain otoprotectants, namely those with quinolone rings, have been observed to confer protection by blocking aminoglycoside entry into hair cells instead of modulating cell death targets (Ou et al., 2009, 2012). To test if Dihexa blocks aminoglycoside uptake by hair cells, we quantified GTTR fluorescence either with or without $1 \mu \mathrm{M}$ Dihexa. GTTR uptake was not altered in the presence of Dihexa, as seen in the qualitative examples and quantitative fluorescence data shown in Figure 4. This result indicates that Dihexa likely protects hair cells by modulating a cell death target.

\section{DIHEXA OTOPROTECTION IS MEDIATED BY HGF/C-MET SIGNALING}

We used the pharmacological inhibitor 6-AH to investigate if the observed protection conferred by Dihexa is actually mediated by $\mathrm{HGF} / \mathrm{c}-\mathrm{Met}$ signaling. 6-AH blocks HGF dimerization and thereby inhibits subsequent c-Met activation (Kawas et al., 2012). Treatment with 6-AH alone does not alter hair cell survival in response to neomycin (Figure 5A). Co-treatment of larvae with 6-AH and Dihexa completely attenuates the hair cell protection conferred by Dihexa treatment (Figure 5B). This observation implicates the requirement of an active $\mathrm{HGF} / \mathrm{c}-\mathrm{Met}$ signal in Dihexa otoprotection.

\section{DOWNSTREAM CELLULAR MEDIATORS OF DIHEXA PROTECTION}

Activation of the receptor tyrosine kinase c-Met leads to the recruitment of many signaling mediators and ultimately the activation of downstream signals, most notably AktTOR and Ras-ERK (Organ and Tsao, 2011). The MAPK and Akt inhibitors, UO126 and Akt inhibitor VIII respectively, were used to determine to what extent, if any, activation of their targets is required for Dihexa-mediated protection. Optimal concentrations of UO126 and Akt Inhibitor VIII 
A
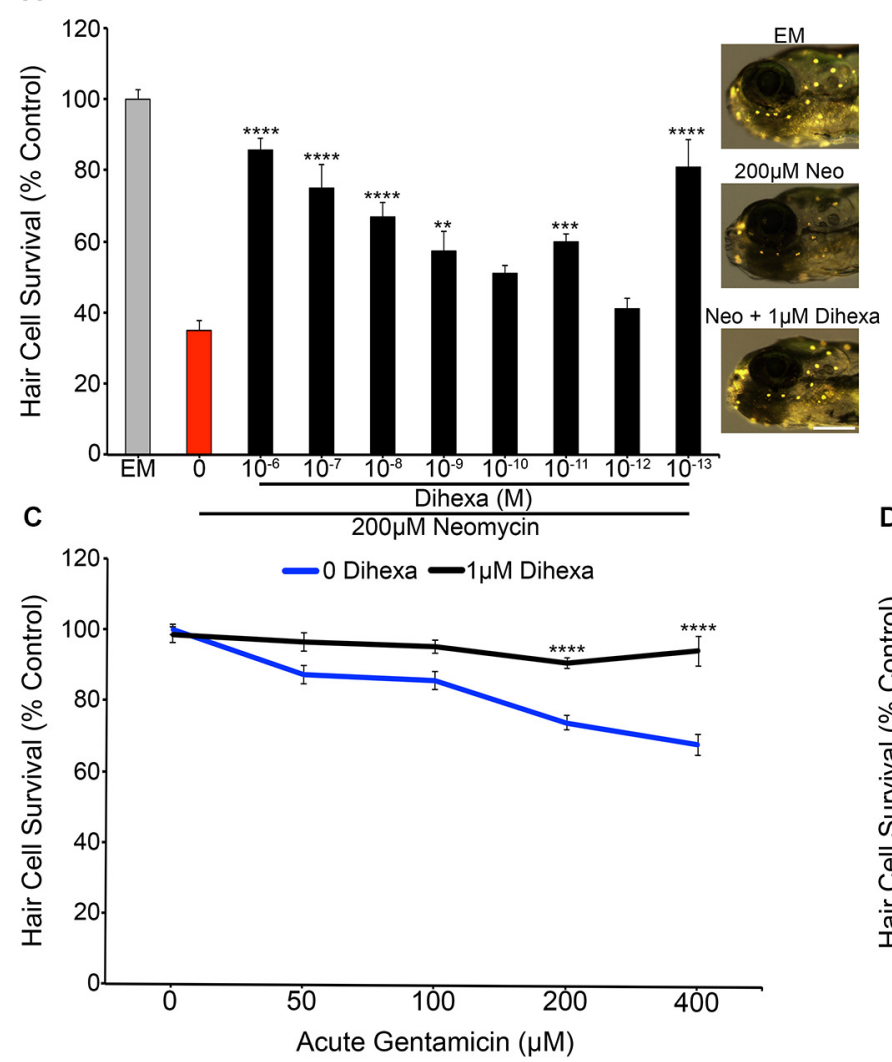

FIGURE 2 | Dihexa protects hair cells from acute aminoglycoside treatment. (A) Dihexa confers dose-dependent protection from $200 \mu \mathrm{M}$ neomycin with two peaks of protection at $10^{-6} \mathrm{M}(1 \mu \mathrm{M})$ and $10^{-13} \mathrm{M}$ (100 fM), with six concentrations of Dihexa providing significant protection (One-way ANOVA; $F_{(9,70)}=20.53 p<0.001$ ). Control fish exposed to embryo medium (EM) only (inset top) and $1 \mu \mathrm{M}$ Dihexa plus $200 \mu \mathrm{M}$ neomycin (inset bottom) display bright DASPEI fluorescence while fish treated with $200 \mu \mathrm{M}$ neomycin alone (inset middle) display dim to absent DASPEI fluorescence. Scale bar represents $250 \mu \mathrm{m}$ and applies to all three images in (A). (B) $1 \mu \mathrm{M}$ Dihexa provides robust protection

$(1 \mu \mathrm{M})$ were determined based on the highest concentration of each compound that did not shift the neomycin doseresponse curve (data not shown). At neomycin concentrations of 100,200 , and $400 \mu \mathrm{M}$ either inhibitor demonstrated partial attenuation of Dihexa otoprotection, indicating at least partial reliance on their associated signaling proteins for protective effects (Figure 6A). Interestingly, when both inhibitors are co-administered the result is similar to each administered independently, suggesting that other signaling proteins may also contribute to protection (data not shown). Phosphorylation of Akt leads to activation of TOR, a molecular sensor of metabolism and cellular homeostasis (Wullschleger et al., 2006). We used the TOR inhibitor rapamycin to determine the extent to which activation of TOR is required in Dihexamediated protection. $10 \mu \mathrm{M}$ rapamycin alone did not affect the neomycin dose-response curve (Figure 6B). However, cotreatment with $1 \mu \mathrm{M}$ Dihexa and $10 \mu \mathrm{M}$ rapamycin showed significant attenuation of hair cell protection at 50 and
B

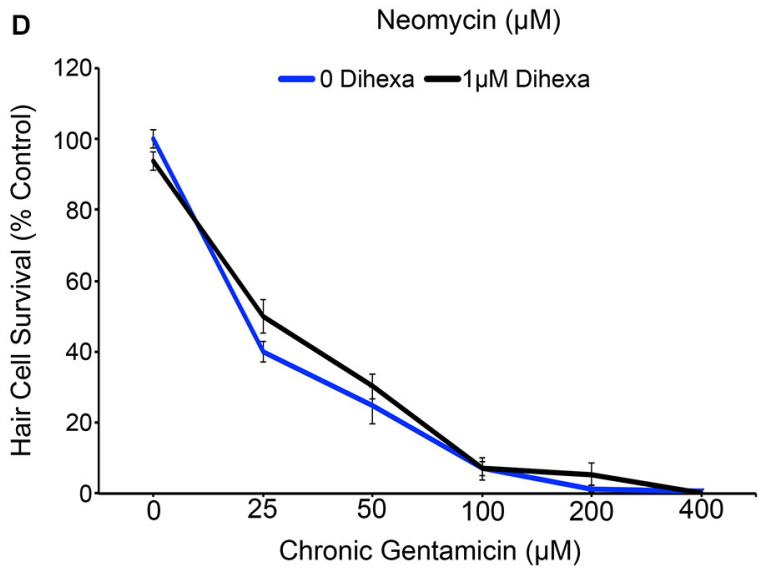

from aminoglycoside treatment across multiple concentrations of neomycin (Two-way ANOVA; Dihexa: $F_{(1,63)}=155.8 p<0.001$ ). (C) $1 \mu \mathrm{M}$ Dihexa confers significant protection from acute gentamicin exposure across all concentrations of gentamicin tested (Two-way ANOVA; Dihexa: $\left.F_{(1,71)}=58.42 p<0.001\right)$. (D) $1 \mu \mathrm{M}$ Dihexa does not provide protection against chronic gentamicin exposure (Two-way ANOVA; Dihexa: $\left.F_{(1,81)}=1.458 p>0.05\right)$. Asterisks indicate significant difference from aminoglycoside only control $\left({ }^{*} p<0.05,{ }^{* *} p<0.01,{ }^{* * *} p<0.005\right.$, ***** $p<0.001$ ). $N=7-11$ animals per treatment, error bars represent \pm s.e.m.
$100 \mu \mathrm{M}$ neomycin. From these results we hypothesize that Dihexa-mediated protection relies, at least in part, on the activation of multiple downstream targets of the HGF/c-Met system (Akt-TOR and Ras-ERK).

\section{MODIFIED DIHEXA IS NOT A HAIR CELL PROTECTANT}

To test the specificity of Dihexa for the observed protection, we synthesized an additional Dihexa variant that was missing an $\mathrm{N}$ terminal amino group. We tested the modified Dihexa against $200 \mu \mathrm{M}$ neomycin and observed no protection, suggesting that the current form of Dihexa has a high specificity for providing protection, likely via its specific interaction with native HGF (Figure 7).

\section{DIHEXA DOES NOT PROTECT HAIR CELLS FROM CISPLATIN}

Previous work with chemical and genetic cell death modulators suggests that cisplatin and aminoglycosides share some cell death pathways while also activating a distinct subset of signaling 

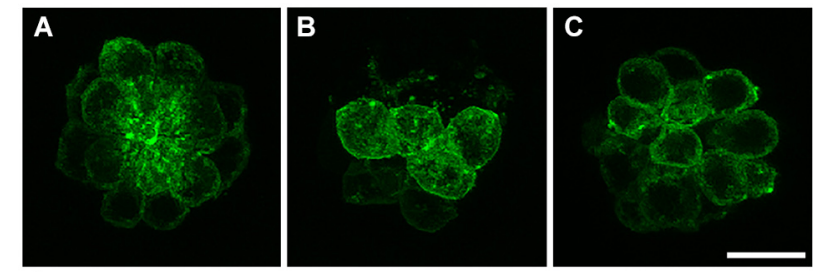

D

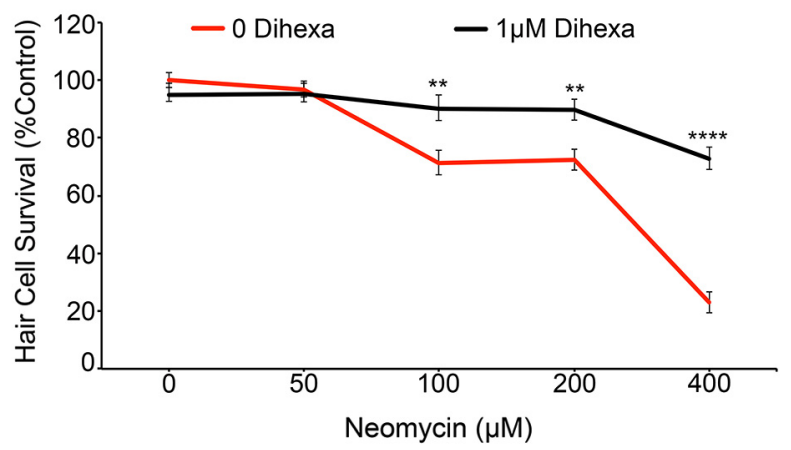

FIGURE 3 | Dihexa treatment prevents neomycin-induced hair cell loss in Brn3c:mGFP transgenic larvae. (A) DMSO-treated control, (B) $400 \mu \mathrm{M}$ neomycin treated neuromast shows a reduction in hair cells, and

(C) neuromasts treated with $1 \mu \mathrm{M}$ Dihexa plus $400 \mu \mathrm{M}$ neomycin remain mostly intact. (D) $1 \mu \mathrm{M}$ Dihexa provides protection from neomycin-induced hair cell loss across the neomycin dose-response curve (Two-way ANOVA; Dihexa: $\left.F_{(1,456)}=50.77 p<0.001\right)$. Asterisks indicate significant difference from neomycin control $\left.{ }^{* *} p<0.01,{ }^{* * * *} p<0.001\right) . N=8-10$ animals per treatment, error bars represent \pm s.e.m.

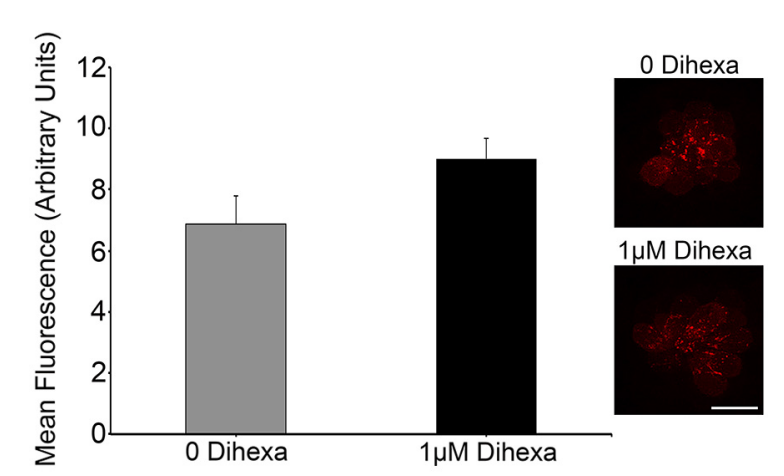

FIGURE 4 | Dihexa does not block aminoglycoside entry into hair cells. There was no significant difference in quantified GTTR fluorescence within neuromasts of animals treated with or without $1 \mu \mathrm{M}$ Dihexa ( $t$-test; $p=0.1158$ ). Sample control neuromast with bright GTTR fluorescence (inset top) is qualitatively the same intensity as a neuromast treated with $1 \mu \mathrm{M}$ Dihexa (inset bottom). Scale bar represents $10 \mu \mathrm{m}$ and applies to both images. $N=8$ animals per treatment, error bars represent \pm s.e.m.

pathways (Owens et al., 2008; Vlasits et al., 2012; Coffin et al., 2013b). Animals exposed to Dihexa exhibit no shift in the cisplatin dose-response curve (Figure 8). This result signifies that Dihexa's protection is likely by mediating the response of an aminoglycoside-specific target that is not shared by cisplatin.

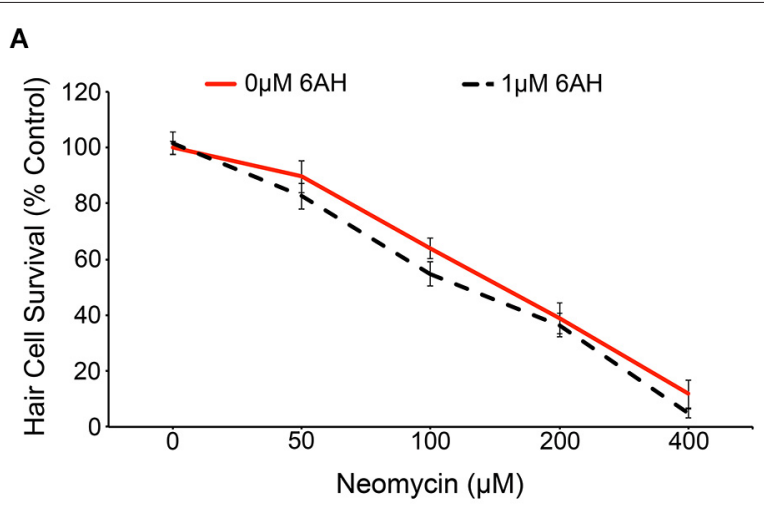

B

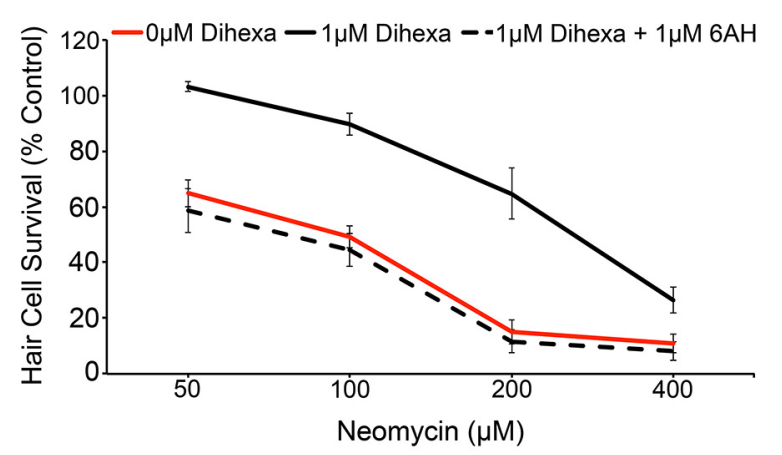

FIGURE 5 | Dihexa-mediated protection is inhibited by the HGF antagonist 6-AH. (A) Treatment with $1 \mu \mathrm{M}$ 6-AH does not alter lateral line hair cell survival in response to neomycin (Two-way ANOVA; 6-AH: $\left.F_{(1,72)}=3.255 p=0.0754\right)$. (B) Treatment with $1 \mu \mathrm{M}$ Dihexa decreases neomycin-induced hair cell death over multiple concentrations of neomycin. Co-treatment with 6-AH completely attenuates Dihexa-mediated protection (Two-way ANOVA; Dihexa: $F_{(2,76)}=76.30 p<0.001$ ). There is a significant difference ( $p<0.001$ ) when comparing $1 \mu \mathrm{M}$ Dihexa vs. $1 \mu \mathrm{M}$ Dihexa plus $1 \mu \mathrm{M}$ 6-AH at 50, 100, and $200 \mu \mathrm{M}$ neomycin treatment groups, $p<0.05$ at $400 \mu \mathrm{M}$ neomycin. $N=6-9$ animals per treatment, error bars represent \pm s.e.m.

\section{DISCUSSION}

We show that the HGF mimetic Dihexa protects lateral line hair cells from acute aminoglycoside ototoxicity. Previous work has reported that $\mathrm{HGF} / \mathrm{c}-\mathrm{Met}$ activation can confer hair cell protection from aminoglycoside damage, consistent with our results (Monahan and Samulski, 2000; Oshima et al., 2004; Kikkawa et al., 2009). However, the innate chemical properties of HGF, such as a short half-life, make it a poor therapeutic option (Appasamy et al., 1993). Additionally, HGF synthesis is prohibitively expensive, similar to other proteinderived neurotrophic factors (Swartz, 2001). These obstacles can be overcome by Dihexa, a synthetic, small molecule HGF mimetic that is orally bioavailable, metabolically stable, blood-brain barrier permeable, and inexpensive to synthesize (McCoy et al., 2013). Treatment with Dihexa has been shown to reliably activate c-Met activity through HGF-dependent interactions (Benoist et al., 2014). We think Dihexa represents an exciting new drug candidate for attenuating aminoglycoside ototoxicity. 


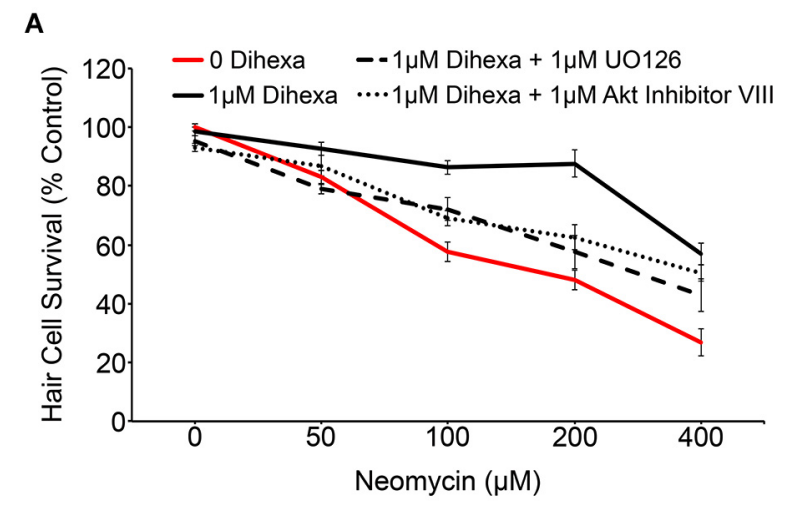

B

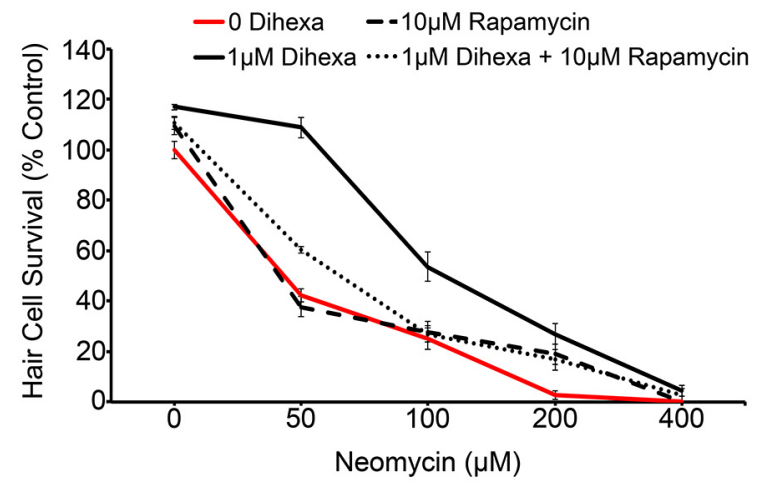

FIGURE 6 | Dihexa-mediated protection is inhibited by MEK, Akt, and TOR inhibitors. (A) Co-treatment with $1 \mu \mathrm{M}$ MEK or Akt inhibitors (UO126 and Akt Inhibitor VIII, respectively) partially attenuates Dihexa-dependent protection (Two-way ANOVA; Dihexa: $F_{(3,144)}=37.13 p<0.001$ ). When comparing the $1 \mu \mathrm{M}$ Dihexa treatment vs. $1 \mu \mathrm{M}$ Dihexa plus $1 \mu \mathrm{M}$ U0126 $p$-values are as follows: $50 \mu \mathrm{M}$ neomycin $(p<0.05), 100 \mu \mathrm{M}$ neomycin ( $p<0.05), 200 \mu \mathrm{M}$ neomycin $(p<0.001)$, and $400 \mu \mathrm{M}$ neomycin $(p<0.05)$. When comparing the $1 \mu \mathrm{M}$ Dihexa treatment vs. $1 \mu \mathrm{M}$ Dihexa plus $1 \mu \mathrm{M}$ Akt inhibitor VIII p-values are as follows: $50 \mu \mathrm{M}$ neomycin $(p>0.05), 100 \mu \mathrm{M}$ neomycin $(p<0.05), 200 \mu \mathrm{M}$ neomycin $(p<0.001)$, $400 \mu \mathrm{M}$ neomycin $(p>0.05)$. (B) Co-treatment with $10 \mu \mathrm{M}$ of the TOR inhibitor, rapamycin, also partially attenuates Dihexa-mediated protection from neomycin (Two-way ANOVA; Dihexa: $F_{(3,120)}=70.41 p<0.001$ ). When comparing the $1 \mu \mathrm{M}$ Dihexa treatment vs. $1 \mu \mathrm{M}$ Dihexa plus $10 \mu \mathrm{M}$ rapamycin $p$-values were as follows: $50 \mu \mathrm{M}$ neomycin $(p<0.001), 100 \mu \mathrm{M}$ neomycin ( $p<0.001), 200$ and $400 \mu \mathrm{M}$ neomycin $(p>0.05) . N=6-9$ animals per treatment, error bars represent \pm s.e.m.

Attenuation of aminoglycoside-induced hair cell death can result from two mechanistic categories: blockage of aminoglycoside uptake by hair cells or modulation of intracellular signaling pathways. Functional mechanotransduction is a known requirement for aminoglycoside entry into hair cells and its resulting ototoxicity (Alharazneh et al., 2011; Vu et al., 2013). Some compounds that protect hair cells from aminoglycoside exposure, for example tacrine and other quinoline ringcontaining structures, do so by inhibiting aminoglycoside uptake (Ou et al., 2009, 2012). Even compounds with known intracellular targets, such as the estrogen receptor modulator raloxifene, may protect hair cells by inhibiting aminoglycoside entry, rather than acting via modulation of estrogen signaling (Vlasits et al., 2012). Here, we measured

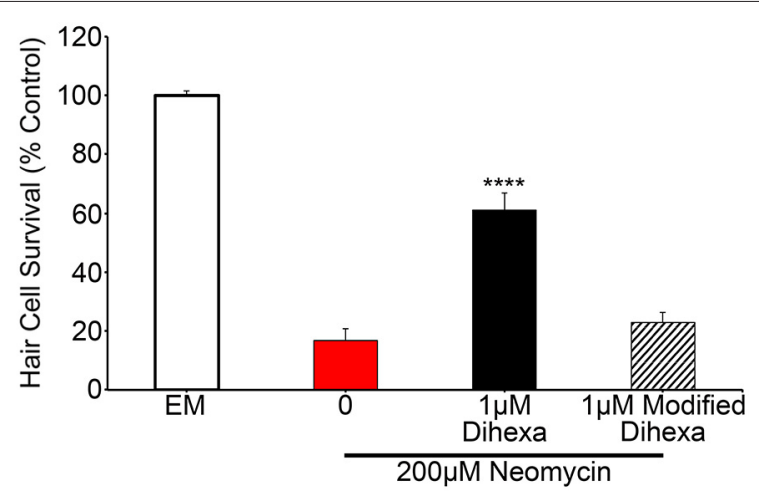

FIGURE 7 | A Dihexa variant that is missing an $\mathrm{N}$-terminal amino group (modified) does not provide protection against $200 \mu \mathrm{M}$ neomycin. $1 \mu \mathrm{M}$ Dihexa provides robust protection from $200 \mu \mathrm{M}$ neomycin ( $t$-test; $p<0.001$ ) whereas $1 \mu \mathrm{M}$ of modified Dihexa provides no significant protection ( $p=0.34$ ) when compared to $200 \mu \mathrm{M}$ neomycin. Asterisks indicate significant difference from $200 \mu \mathrm{M}$ neomycin control $\left.{ }^{* * * * *} p<0.001\right) . N=7$ animals per treatment, error bars represent \pm s.e.m.

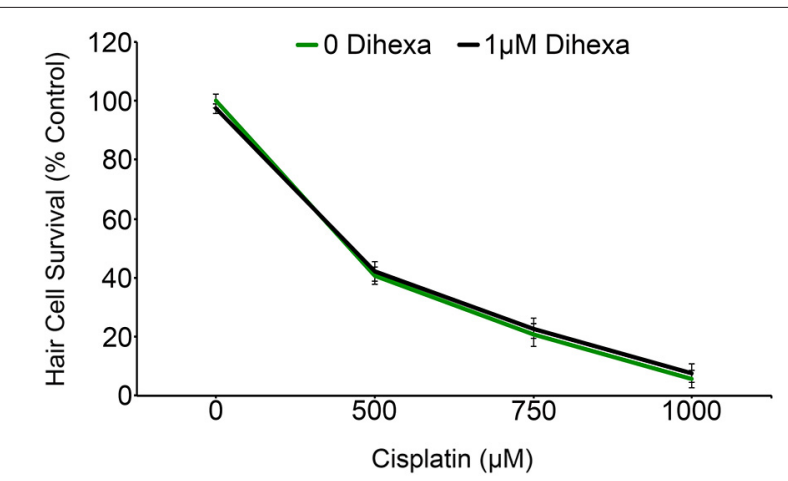

FIGURE 8 | Dihexa confers no protection from cisplatin ototoxicity. Cisplatin dose-response curves with and without dihexa are nearly identical (Two-way ANOVA; Dihexa: $F_{(1,39)}=0.1845 p=0.6699$ ). $N=5-7$ animals per treatment, error bars represent \pm s.e.m.

no difference in aminoglycoside uptake in hair cells treated with or without Dihexa, suggesting that Dihexa confers protection by modulation of cellular targets rather than blocking aminoglycoside uptake.

HGF/c-Met activates a diverse set of signal transducers capable of inhibiting cell death. For example, in various cell culture lines, c-Met phosphorylation can result in downstream activation of Akt, Erk/MAPK, JNK, or FAK signaling (reviewed by Organ and Tsao, 2011). We found that Dihexa-mediated protection requires activation of Akt, TOR, and MEK signaling, as inhibition of any of these targets attenuates Dihexa-mediated protection. Similarly, Insulin-like growth factor 1 hair cell protection from neomycin damage is lost by inhibition of Akt or MEK signaling, suggesting that growth factor otoprotection may operate on a similar set of downstream targets (Hayashi et al., 2013). Endogenous Akt activation also plays a survival role in cochlear hair cells in response to gentamicin ototoxicity (Chung et al., 2006). Activation of Akt or MEK in cell culture can prevent 
proteolytic cleavage of pro-caspase-9 thereby inhibiting classical caspase-dependent apoptosis (Cardone et al., 1998; Allan et al., 2003). The necessity of caspase activation for aminoglycosideinduced hair cell death is still debatable, so alternative, caspaseindependent pathways may lie downstream of Dihexa-mediated protection (Cunningham et al., 2002; Matsui et al., 2003; Jiang et al., 2006; Coffin et al., 2013b). The pro-survival protein Bcl-2 regulates cell death by inhibiting pro-cell death members of the Bcl-2 family of proteins (Reviewed by Czabotar et al., 2014). Both HGF application and Akt activity result in increased Bcl-2 expression in cell culture (Pugazhenthi et al., 2000; Gordin et al., 2010). In human endothelial cells, HGFinduced cellular protection from hypoxia is dependent on Bcl-2 activity (Yamamoto et al., 2001). Bcl-2 overexpression protects hair cells from aminoglycoside exposure both in vitro and in vivo (Cunningham et al., 2004; Pfannenstiel et al., 2009; Coffin et al., 2013a). Given the complexity of signal modulators downstream of $\mathrm{HGF} / \mathrm{c}-\mathrm{Met}$, additional work is needed to better understand what processes are important for Dihexa's hair cell protection.

Understanding hair cell death mechanisms activated by specific ototoxins can help shed light on what molecular signals to therapeutically target for each toxic agent. Dihexa treatment protected hair cells from acute aminoglycoside treatment (neomycin or gentamicin) but conferred no protection from chronic gentamicin or cisplatin exposure. These data are consistent with known differences in cell death signals activated across these three groups (cisplatin, acute aminoglycosides, and chronic aminoglycosides). There are at least two processes of aminoglycoside-induced cell death that depend on both the particular aminoglycoside and exposure time (Coffin et al., 2009; Owens et al., 2009). Pharmacological inhibition of Bax, a Bcl-2 family member that promotes cell death, prevents neomycin but not gentamicin ototoxicity in zebrafish (Coffin et al., 2013a,b). In contrast, inhibition of p53 protects lateral line hair cells from acute neomycin or gentamicin as well as chronic gentamicin exposure (Coffin et al., 2013a). A previously identified hair cell protectant, PROTO1, showed robust protection from acute aminoglycoside exposure but only modest protection from the chronic process and offered no protection against cisplatin, similar to the result demonstrated here with Dihexa (Owens et al., 2008). Additionally, Vlasits et al. also identified multiple compounds from a FDA-approved drug screen with very similar protection profiles to Dihexa (Vlasits et al., 2012). These results describe a system of aminoglycoside-induced cell death that both shares molecular targets but also has unique features depending on aminoglycoside and exposure time. Dihexa's protection from acute but not chronic aminoglycoside exposure further strengthens the two-phase model of aminoglycoside induced-hair cell death.

Future work will address the efficacy of Dihexa as a hair cell protect in mammalian models and against additional aminoglycosides. In summary, our study identifies a new hair cell protectant, Dihexa, that relies upon HGF/c-Met signal transduction for its protection. Due to its conscious design as an orally bioavailable compound, Dihexa is a strong clinical candidate as a hair cell protectant.

\section{AUTHOR CONTRIBUTIONS}

Participated in research design: Phillip M. Uribe, Leen H. Kawas, Joseph W. Harding, Allison B. Coffin.

Conducted experiments: Phillip M. Uribe, Leen H. Kawas, Joseph W. Harding, Allison B. Coffin.

Performed data analysis: Phillip M. Uribe, Allison B. Coffin.

Wrote or contributed to the writing of the manuscript: Phillip

M. Uribe, Leen H. Kawas, Joseph W. Harding, Allison B. Coffin.

\section{ACKNOWLEDGMENTS}

We thank Lauren Hayashi for assistance with experiments and Chris Riso for fish husbandry support. We would also like to thank Dr. Barb Sorg for donating rapamycin. This project was funded by start-up funds from Washington State University, Vancouver to A. Coffin. Additional funding for this project was provided by M3 Biotechnology, Inc.

\section{REFERENCES}

Alharazneh, A., Luk, L., Huth, M., Monfared, A., Steyger, P. S., Cheng, A. G., et al. (2011). Functional hair cell mechanotransducer channels are required for aminoglycoside ototoxicity. PLoS one 6:e22347. doi: 10.1371/journal.pone. 0022347

Allan, L. A., Morrice, N., Brady, S., Magee, G., Pathak, S., and Clarke, P. R. (2003). Inhibition of caspase- 9 through phosphorylation at Thr 125 by ERK MAPK. Nat. Cell Biol. 5, 647-654. doi: 10.1038/ncb1005

Appasamy, R., Tanabe, M., Murase, N., Zarnegar, R., Van Thiel, D. H., and Michalopoulos, G. K. (1993). Hepatocyte growth factor, blood clearance, organ uptake and biliary excretion in normal and partially hepatectomized rats. Lab. Invest. 68, 270-276.

Benoist, C. C., Kawas, L. H., Zhu, M., Tyson, K. A., Stillmaker, L., Appleyard, S. M. et al. (2014). The pro-cognitive and synaptogenic effects of angiotensin IVderived peptides are dependent on activation of the hepatocyte growth factor/cMet system. J. Pharmacol. Exp. Ther. 351, 390-402. doi: 10.1124/jpet.114.218735

Bess, F. H., Lichtenstein, M. J., Logan, S. A., Burger, M. C., and Nelson, E. (1989). Hearing impairment as a determinant of function in the elderly. J. Am. Geriatr. Soc. 37, 123-128.

Cardone, M., Roy, N., Stennicke, H., Salvesen, G., Franke, T., Stanbridge, E., et al. (1998). Regulation of cell death protease caspase-9 by phosphorylation. Science 282, 1318-1321. doi: 10.1126/science.282.5392.1318

Cheng, A. G., Johnston, P. R., Luz, J., Uluer, A., Fligor, B., Licameli, G. R., et al. (2009). Sensorineural hearing loss in patients with cystic fibrosis. Otolaryngol. Head Neck Surg. 141, 86-90. doi: 10.1016/j.otohns.2009.03.020

Chung, W. H., Pak, K., Lin, B., Webster, N., and Ryan, A. F. (2006). A PI3K pathway mediates hair cell survival and opposes gentamicin toxicity in neonatal rat organ of Corti. J. Assoc. Res. Otolaryngol. 7, 373-382. doi: 10.1007/s10162-006-0050-y

Coffin, A., Ou, H., Owens, K., Santos, F., Simon, J., Rubel, E., et al. (2010). Chemical screening for hair cell loss and protection in the zebrafish lateral line. Zebrafish 7, 3-11. doi: 10.1089/zeb.2009.0639

Coffin, A. B., Reinhart, K. E., Owens, K. N., Raible, D. W., and Rubel, E. W. (2009). Extracellular divalent cations modulate aminoglycoside-induced hair cell death in the zebrafish lateral line. Hear. Res. 253, 42-51. doi: 10.1016/j.heares.2009.03. 004

Coffin, A. B., Rubel, E. W., and Raible, D. W. (2013a). Bax, Bcl2 and p53 differentially regulate neomycin- and gentamicin-induced hair cell death in the zebrafish lateral line. J. Assoc. Res. Otolaryngol. 14, 645-659. doi: 10. 1007/s10162-013-0404-1

Coffin, A. B., Williamson, K. L., Mamiya, A., Raible, D. W., and Rubel, E. W. (2013b). Profiling drug-induced cell death pathways in the zebrafish lateral line. Apoptosis 18, 393-408. doi: 10.1007/s10495-013-0816-8

Coombs, S., Gorner, P., and Munz, H. (1989). "A brief overview of the mechanosensory lateral line system and the contributions to this volume," in The Mechanosensory Lateral Line: Neurobiology and Evolution (New York: Springer), 3-5. doi: 10.1007/978-1-4612-3560-6_1

Cunningham, L. L., Cheng, A. G., and Rubel, E. W. (2002). Caspase activation in hair cells of the mouse utricle exposed to neomycin. J. Neurosci. 22, 8532-8540. 
Cunningham, L. L., Matsui, J. I., Warchol, M. E., and Rubel, E. W. (2004). Overexpression of Bcl-2 prevents neomycin-induced hair cell death and caspase9 activation in the adult mouse utricle in vitro. J. Neurobiol. 60, 89-100. doi: 10. 1002/neu.20006

Czabotar, P. E., Lessene, G., Strasser, A., and Adams, J. M. (2014). Control of apoptosis by the BCL-2 protein family: implications for physiology and therapy. Nat. Rev. Mol. Cell Biol. 15, 49-63. doi: 10.1038/nrm3722

Ebens, A., Brose, K., Leonardo, E. D., Hanson, M. G., Bladt, F., Birchmeier, C., et al. (1996). Hepatocyte growth factor/scatter factor is an axonal chemoattractant and a neurotrophic factor for spinal motor neurons. Neuron 17, 1157-1172. doi: 10.1016/s0896-6273(00)80247-0

Esterberg, R., Coffin, A., Ou, H., Simon, J., Raible, D., and Rubel, E. (2013). Fish in a dish: drug discovery for hearing habilitation. Drug Discov. Today Dis. Models 10, e23-e29. doi: 10.1016/j.ddmod.2012.02.001

Fee, W. E. (1980). Aminoglycoside ototoxicity in the human. Laryngoscope 90(Suppl. 24), 1-19. doi: 10.1288/00005537-198010001-00001

Gordin, M., Tesio, M., Cohen, S., Gore, Y., Lantner, F., Leng, L., et al. (2010). cMet and its ligand hepatocyte growth factor/scatter factor regulate mature B cell survival in a pathway induced by CD74. J. Immunol. 185, 2020-2031. doi: 10. 4049/jimmunol.0902566

Gupta, T., and Mullins, M. C. (2010). Dissection of organs from the adult zebrafish. J. Vis. Exp. 1717. doi: 10.3791/1717

Harris, J. A., Cheng, A. G., Cunningham, L. L., MacDonald, G., Raible, D. W., and Rubel, E. W. (2003). Neomycin-induced hair cell death and rapid regeneration in the lateral line of zebrafish (Danio rerio). J. Assoc. Res. Otolaryngol. 4, 219234. doi: 10.1007/s10162-002-3022-x

Hayashi, Y., Yamamoto, N., Nakagawa, T., and Ito, J. (2013). Insulin-like growth factor 1 inhibits hair cell apoptosis and promotes the cell cycle of supporting cells by activating different downstream cascades after pharmacological hair cell injury in neonatal mice. Mol. Cell. Neurosci. 56, 29-38. doi: 10.1016/j.mcn.2013. 03.003

Jiang, H., Sha, S.-H. H., Forge, A., and Schacht, J. (2006). Caspase-independent pathways of hair cell death induced by kanamycin in vivo. Cell. Death Differ. 13, 20-30. doi: 10.1038/sj.cdd.4401706

Kawamoto, K., Yagi, M., Stöver, T., Kanzaki, S., and Raphael, Y. (2003). Hearing and hair cells are protected by adenoviral gene therapy with TGF-betal and GDNF. Mol. Ther. 4, 484-492. doi: 10.1016/s1525-0016(03)00058-3

Kawas, L. H., McCoy, A. T., Yamamoto, B. J., Wright, J. W., and Harding, J. W. (2012). Development of angiotensin IV analogs as hepatocyte growth factor/Met modifiers. J. Pharmacol. Exp. Ther. 340, 539-548. doi: 10.1124/jpet.111. 188136

Kikkawa, Y. S., Nakagawa, T., Tsubouchi, H., Ido, A., Inaoka, T., Ono, K., et al. (2009). Hepatocyte growth factor protects auditory hair cells from aminoglycosides. Laryngoscope 119, 2027-2031. doi: 10.1002/lary.20602

Knutson, J. F., and Lansing, C. R. (1990). The relationship between communication problems and psychological difficulties in persons with profound acquired hearing loss. J. Speech Hear. Disord. 55, 656-664. doi: 10.1044/jshd. 5504.656

Liu, Y., Okada, T., Shimazaki, K., Sheykholeslami, K., Nomoto, T., Muramatsu, S., et al. (2008). Protection against aminoglycoside-induced ototoxicity by regulated AAV vector-mediated GDNF gene transfer into the cochlea. Mol. Ther. 3, 474-480. doi: 10.1038/sj.mt.6300379

MacRae, C. A., and Peterson, R. T. (2003). Zebrafish-based small molecule discovery. Chem. Biol. 10, 901-908. doi: 10.1016/j.chembiol.2003.10.003

Matsui, J., Haque, A., Huss, D., Messana, E., Alosi, J., Roberson, D., et al. (2003). Caspase inhibitors promote vestibular hair cell survival and function after aminoglycoside treatment in vivo. J. Neurosci. 23, 6111-6122.

McCoy, A. T., Benoist, C. C., Wright, J. W., Kawas, L. H., Bule-Ghogare, J. M., Zhu, M., et al. (2013). Evaluation of metabolically stabilized angiotensin IV analogs as procognitive/antidementia agents. J. Pharmacol. Exp. Ther. 344, 141154. doi: 10.1124/jpet.112.199497

Miyazawa, T., Matsumoto, K., Ohmichi, H., Katoh, H., Yamashima, T., and Nakamura, T. (1998). Protection of hippocampal neurons from ischemiainduced delayed death by hepatocyte growth factor: a novel neurotrophic factor. J. Cereb. Blood Flow Metab. 18, 345-348. doi: 10.1097/00004647-19980400000001

Monahan, P., and Samulski, R. (2000). Adeno-associated virus vectors for gene therapy: more pros than cons? Mol. Med. Today 6, 433-440. doi: 10.1016/s13574310(00)01810-4
Murakami, S. L., Cunningham, L. L., Werner, L. A., Bauer, E., Pujol, R., Raible, D. W., et al. (2003). Developmental differences in susceptibility to neomycininduced hair cell death in the lateral line neuromasts of zebrafish (Danio rerio). Hear. Res. 186, 47-56. doi: 10.1016/s0378-5955(03)00259-4

Musial-Bright, L., Fengler, R., Henze, G., and Hernáiz Driever, P. (2011). Carboplatin and ototoxicity: hearing loss rates among survivors of childhood medulloblastoma. Childs Nerv. Syst. 27, 407-413. doi: 10.1007/s00381-0101300-1

Niimura, M., Takagi, N., Takagi, K., Funakoshi, H., Nakamura, T., and Takeo, S. (2006). Effects of hepatocyte growth factor on phosphorylation of extracellular signal-regulated kinase and hippocampal cell death in rats with transient forebrain ischemia. Eur. J. Pharmacol. 535, 114-124. doi: 10.1016/j.ejphar.2006. 01.037

Organ, S. L., and Tsao, M.-S. S. (2011). An overview of the c-MET signaling pathway. Ther. Adv. Med. Oncol. 3, S7-S19. doi: 10.1177/17588340114 22556

Oshima, K., Shimamura, M., Mizuno, S., Tamai, K., Doi, K., Morishita, R., et al. (2004). Intrathecal injection of HVJ-E containing HGF gene to cerebrospinal fluid can prevent and ameliorate hearing impairment in rats. FASEB J. 18, 212214. doi: 10.1096/fj.03-0567fje

Ou, H. C., Cunningham, L. L., Francis, S. P., Brandon, C. S., Simon, J. A., Raible, D. W., et al. (2009). Identification of FDA-approved drugs and bioactives that protect hair cells in the zebrafish (Danio rerio) lateral line and mouse (Mus musculus) utricle. J. Assoc. Res. Otolaryngol. 10, 191-203. doi: 10.1007/s10162009-0158-y

Ou, H. C., Keating, S., Wu, P., Simon, J. A., Raible, D. W., and Rubel, E. W. (2012). Quinoline ring derivatives protect against aminoglycoside-induced hair cell death in the zebrafish lateral line. J. Assoc. Res. Otolaryngol. 13, 759-770. doi: 10.1007/s10162-012-0353-0

Ou, H. C., Raible, D. W., and Rubel, E. W. (2007). Cisplatin-induced hair cell loss in zebrafish (Danio rerio) lateral line. Hear. Res. 233, 46-53. doi: 10.1016/j.heares. 2007.07.003

Owens, K. N., Coffin, A. B., Hong, L. S., Bennett, K. O., Rubel, E. W., and Raible, D. W. (2009). Response of mechanosensory hair cells of the zebrafish lateral line to aminoglycosides reveals distinct cell death pathways. Hear. Res. 253, 32-41. doi: 10.1016/j.heares.2009.03.001

Owens, K. N., Santos, F., Roberts, B., Linbo, T., Coffin, A. B., Knisely, A. J., et al. (2008). Identification of genetic and chemical modulators of zebrafish mechanosensory hair cell death. PLoS Genet. 4:e1000020. doi: 10.1371/journal. pgen. 1000020

Pfannenstiel, S., Praetorius, M., Plinkert, P., Brough, D., and Staecker, H. (2009). $\mathrm{Bcl}-2$ genet therapy prevents aminoglycoside-induced degeneration of auditory and vestibular hair cells. Audiol. Neurotol. 14, 254-266. doi: 10.1159/0001 92953

Pugazhenthi, S., Nesterova, A., Sable, C., Heidenreich, K. A., Boxer, L. M., Heasley, L. E., et al. (2000). Akt/protein kinase B up-regulates Bcl-2 expression through cAMP-response element-binding protein. J. Biol. Chem. 275, 10761-10766. doi: 10.1074/jbc.275.15.10761

Raible, D. W., and Kruse, G. J. (2000). Organization of the lateral line system in embryonic zebrafish. J. Comp. Neurol. 421, 189-198. doi: 10.1002/(sici)10969861(20000529)421:2<189::aid-cne5>3.3.co;2-b

Rubel, E. W., Robbin, C., Owens, K. N., Raible, D. W., and Simon, J. A. (2011). "PROTO1 provides robust protection against kanamycin-induced hearing loss in rats," in Proceedings of the Association for Research in Otolaryngology Annual Meeting (Baltimore, MD).

Rybak, L. P. (2007). Mechanisms of cisplatin ototoxicity and progress in otoprotection. Curr. Opin. Otolaryngol. Head Neck Surg. 15, 364-369. doi: 10. 1097/moo.0b013e3282eee452

Rybak, L. P., Mukherjea, D., Jajoo, S., and Ramkumar, V. (2009). Cisplatin ototoxicity and protection: clinical and experimental studies. Tohoku J. Exp. Med. 219, 177-186. doi: 10.1620/tjem.219.177

Santos, F., MacDonald, G., Rubel, E. W., and Raible, D. W. (2006). Lateral line hair cell maturation is a determinant of aminoglycoside susceptibility in zebrafish (Danio rerio). Hear. Res. 213, 25-33. doi: 10.1016/j.heares.2005. 12.009

Shoji, F., Yamasoba, T., Magal, E., Dolan, D., Altschuler, R., and Miller, J. (2000). Glial cell line-derived neurotrophic factor has a dose dependent influence on noise-induced hearing loss in the guinea pig cochlea. Hear. Res. 142, 41-55. doi: 10.1016/s0378-5955(00)00007-1 
Steyger, P. S., Peters, S. L., Rehling, J., Hordichok, A., and Dai, C. F. (2003). Uptake of gentamicin by bullfrog saccular hair cells in vitro. J. Assoc. Res. Otolaryngol. 4, 565-578. doi: 10.1007/s10162-003-4002-5

Swartz, J. R. (2001). Advances in Escherichia coli production of therapeutic proteins. Curr. Opin. Biotechnol. 12, 195-201. doi: 10.1016/s0958-1669(00)00199-3

Uribe, P. M., Mueller, M. A., Gleichman, J. S., Kramer, M. D., Wang, Q., SibrianVazquez, M., et al. (2013). Dimethyl sulfoxide (DMSO) exacerbates cisplatininduced sensory hair cell death in zebrafish (Danio rerio). PLoS One 8:e55359. doi: 10.1371/journal.pone.0055359

Vlasits, A. L., Simon, J. A., Raible, D. W., Rubel, E. W., and Owens, K. N. (2012). Screen of FDA-approved drug library reveals compounds that protect hair cells from aminoglycosides and cisplatin. Hear. Res. 294, 153-165. doi: 10.1016/j. heares.2012.08.002

Vu, A. A., Nadaraja, G. S., Huth, M. E., Luk, L., Kim, J., Chai, R., et al. (2013). Integrity and regeneration of mechanotransduction machinery regulate aminoglycoside entry and sensory cell death. PLoS One 8:e54794. doi: 10. 1371/journal.pone.0054794

Westerfield, M. (2000). The Zebrafish Book: A Guide for the Laboratory Use of Zebrafish (Danio Rerio). Eugene: University of Oregon.

Wullschleger, S., Loewith, R., and Hall, M. (2006). TOR signaling in growth and metabolism. Cell 124, 471-484. doi: 10.1016/j.cell.2006.01.016

Xiao, T., Roeser, T., Staub, W., and Baier, H. (2005). A GFP-based genetic screen reveals mutations that disrupt the architecture of the zebrafish retinotectal projection. Development 132, 2955-2967. doi: 10.1242/dev.01861

Yagi, M., Magal, E., Sheng, Z., Ang, K. A., and Raphael, Y. (1999). Hair cell protection from aminoglycoside ototoxicity by adenovirus-mediated overexpression of glial cell line-derived neurotrophic factor. Hum. Gene Ther. 10, 813-823. doi: 10.1089/10430349950018562
Yamamoto, K., Morishita, R., Hayashi, S., Matsushita, H., Nakagami, H., Moriguchi, A., et al. (2001). Contribution of Bcl-2, but not Bcl-xL and Bax, to antiapoptotic actions of hepatocyte growth factor in hypoxia-conditioned human endothelial cells. Hypertension 37, 1341-1348. doi: 10.1161/01.hyp.37. 5.1341

Zhang, L., Himi, T., Morita, I., and Murota, S. (2000). Hepatocyte growth factor protects cultured rat cerebellar granule neurons from apoptosis via the phosphatidylinositol 3 kinase/Akt pathway. J. Neurosci. Res. 59, 489-496. doi: 10. 1002/(SICI) 1097-4547(20000215)59:4<489::AID-JNR3>3.0.CO;2-9

Conflict of Interest Statement: Joseph W. Harding is co-founder and shareholder of M3 Biotechnology, Inc. Leen H. Kawas is the CEO of M3 Biotechnology, Inc. M3 Biotechnology, Inc. is developing HGF mimetics and antagonists for the treatment of various disorders including dementia. Phillip M. Uribe and Allison B. Coffin hold no competing interests.

Received: 25 September 2014; accepted: 05 January 2015; published online: 28 January 2015.

Citation: Uribe PM, Kawas LH, Harding JW and Coffin AB (2015) Hepatocyte growth factor mimetic protects lateral line hair cells from aminoglycoside exposure. Front. Cell. Neurosci. 9:3. doi: 10.3389/fncel.2015.00003

This article was submitted to the journal Frontiers in Cellular Neuroscience.

Copyright (c) 2015 Uribe, Kawas, Harding and Coffin. This is an open-access article distributed under the terms of the Creative Commons Attribution License (CC BY). The use, distribution and reproduction in other forums is permitted, provided the original author(s) or licensor are credited and that the original publication in this journal is cited, in accordance with accepted academic practice. No use, distribution or reproduction is permitted which does not comply with these terms. 